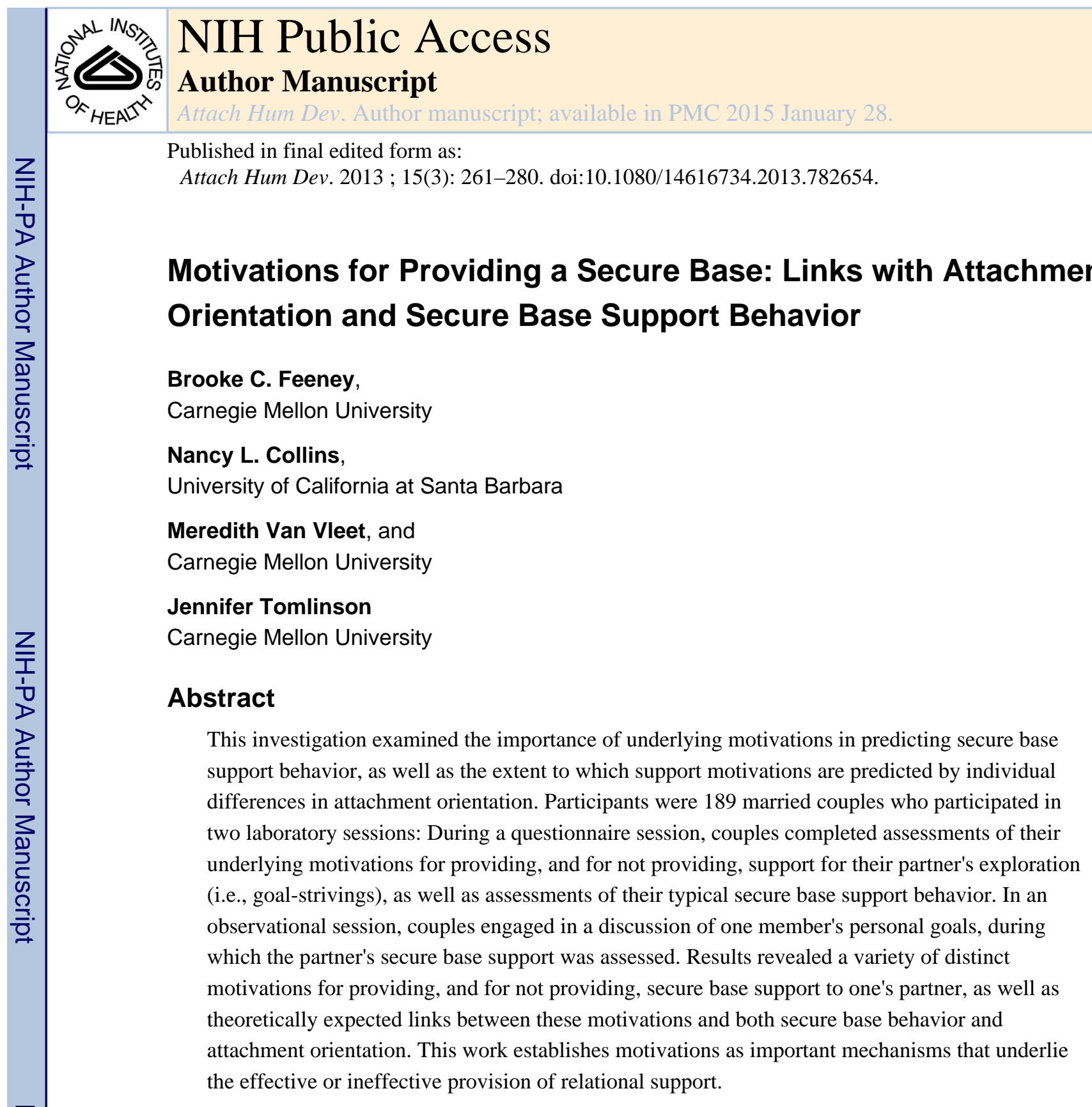

\title{
Keywords
}

motivations; secure base; caregiving; social support; attachment; exploration; goals

\begin{abstract}
Although individuals routinely assign credit for their accomplishments to the support of the significant people in their lives, research examining this important type of support has been scarce in both the relationships and social support literatures. Historically, the social support literature has focused on one general type of support, which is the comfort and assistance that is provided to another person in stressful situations. However, research examining the support of a relationship partner's personal growth, exploration, and goal strivings has been lacking. The goal of this investigation is to contribute to narrowing this gap in the literature
\end{abstract}

Correspondence concerning this article should be addressed to Brooke C. Feeney, Department of Psychology, Carnegie Mellon University, 5000 Forbes Avenue, Pittsburgh, PA 15213. bfeeney@ andrew.cmu.edu. 
by identifying important individual difference factors that may influence the provision of this type of support, which we have referenced as the provision of a secure base consistent with attachment theory's notion of a base that functions to support a relationship partner's autonomous exploration in the environment (Bowlby, 1988; Crowell, Treboux, Gao, Fyffe, Pan, \& Waters, 2002; Feeney, 2004, 2007; Marvin, Cooper, Hoffman, \& Powell, 2002; Waters \& Cummings, 2000). We focus this investigation on support-providers' specific motivations for providing and for not providing support in this context, and we examine links with attachment style and secure base support provision.

\section{Importance of Considering Motivations}

We propose that underlying motivations are important to consider in predicting secure base support provision because support-providers must be especially motivated to deploy their skills and resources in the service of others in this context, which is likely to be perceived as less urgent than providing support in times of stress. We have noted in prior work that because responsive support provision often involves a good deal of responsibility, as well as a substantial amount of cognitive, emotional, and sometimes tangible resources, supportproviders must be motivated to accept that responsibility and to use their skills and resources in the service of another (Feeney \& Collins, 2001, 2003; 2012). Thus, individuals may differ in the degree to which they experience a sense of felt responsibility for the welfare of a relationship partner (Clark \& Mills, 1993; Williamson, Clark, Pegalis, \& Behan, 1996). If support-providers are not sufficiently motivated, then they will be unlikely to provide responsive support (Feeney \& Collins, 2003). Felt responsibility may differ between people (e.g., a general communal orientation), between relationships (e.g., felt responsibility for, and commitment to, a particular partner), or between situations (e.g., heightened sense of responsibility in response to a high level of need). In support of this idea, research has shown that support-providers have different reactions to the suffering of a spouse versus a stranger (Monin, Schulz, Feeney, \& Cook, 2010), and that support-recipients expect different levels of responsibility from others depending on the nature of the relationship (Reis, Clark, \& Holmes, 2004).

Second, even if support-providers are equally motivated to care for a relationship partner in terms of overall felt responsibility, they may differ in the degree to which that motivation is generated by altruistic concerns - the desire to promote another's welfare - or egoistic concerns - the desire to gain explicit benefits for the self or to avoid sanctions (Batson \& Shaw, 1991). In related research, we have shown that specific motivations (e.g., egoistic versus altruistic) for helping one's partner can help explain why people are more or less effective support-providers, and that support motivation levels vary depending on factors such as feelings of responsibility and feelings of love/concern for the person in need (Feeney \& Collins, 2001; 2003). Other work shows that compassionate goals foster mutually supportive friendships whereas self-image goals undermine the development and maintenance of supportive friendships (Canevello \& Crocker, 2010; Crocker \& Canevello, 2008). We propose that the most responsive support providers are those who are more altruistically motivated by empathic concern (Batson \& Shaw, 1991) and more intrinsically motivated (Deci \& Ryan, 2000; Ryan \& Deci, 2000) to care for their partners. In prior research, we have identified motivations that predict the provision of support in times of 
stress (Feeney \& Collins, 2001; Feeney \& Collins, 2003). We predict that underlying motivations are also important mechanisms that shape the quality of secure base support the support of a relationship partner's exploration behavior. Egoistic motivations for helping (i.e., helping as a means to self-benefit) are likely to be associated with unresponsive forms of secure base support (e.g., intrusiveness, discouraging exploration, unavailability), whereas more altruistic motives for helping (i.e., helping in which benefiting the partner is the ultimate goal) are likely to be associated with responsive forms of secure base support (e.g., non-intrusiveness, encouraging exploration, availability).

\section{Attachment Style as a Predictor of Motivations for Providing a Secure Base}

Because not all individuals are equally motivated to provide a secure base for their relationship partners, this investigation considers the extent to which one important individual difference factor - attachment orientation - predicts motivations for providing secure base support. Attachment orientation is examined in this investigation because it has been shown in prior research to predict the provision of responsive or unresponsive support (e.g., Crowell et al., 2002; Feeney \& Collins, 2001; Feeney \& Thrush, 2010; Kunce \& Shaver, 1994; Simpson et al., 1992), and because attachment theory and research (see Cassidy \& Shaver, 2008, and Mikulincer \& Shaver, 2007, for summaries) provides a wealth of information regarding the precursors and consequents of individual differences in attachment that provide a foundation for predicting underlying motives for providing and for not providing a secure base for one's relationship partner.

In recent work, we have described a secure base as being encouraging and non-intrusive during exploration, yet available if needed to assist in removing obstacles (Feeney \& Thrush, 2010), which is consistent with attachment theoretical propositions that a secure base creates the conditions that enable relationship partners to explore the world in a confident way (Bowlby, 1988). Moreover, we have shown that both forms of insecure attachment hinder the provision of responsive secure base support: Support-provider attachment anxiety is linked with less encouragement of exploration and greater interference, whereas support-provider attachment avoidance is linked with a lack of availability during exploration (Feeney $\&$ Thrush, 2010). In addition, insecure supportrecipients have partners who are less available to them and less encouraging during exploration (Feeney \& Thrush, 2010).

What underlying motives should explain these effects? Because anxious attachment is organized by rules that direct attention toward distress and attachment figures in a hypervigilant manner, which inhibits the development of autonomy and self-confidence (e.g., Bartholomew \& Horowitz, 1991; Brennan, Clark, \& Shaver, 1998), we expect that support-providers' anxious attachment will be associated with relatively egoistic motives (for providing secure base support) reflecting a desire to connect with one's partner, a desire to avoid pursuing one's own goals, feeling obligated to support one's partner, wanting to avoid negative consequences for not helping, wanting to keep one's spouse (ensuring the spouse's continued commitment), and wanting to be rewarded in some way. Given their more restricted, self-focused attention (perhaps as a result of constant attachment system activation), anxious support-providers are unlikely to report supporting their partners 
because they love their spouse or enjoy it. When asked why they do not provide a secure base for their partners, anxious individuals are likely to report motives reflecting concerns that supporting a partner's goal-strivings/explorations will take the spouse away, not approving of the spouse's goals, finding the spouse difficult and unreceptive, not knowing how to support the spouse, finding it stressful to provide a secure base, and believing that their support will not help the spouse.

Because avoidant attachment is organized by rules that emphasize independence and that restrict intimacy, acknowledgement of distress, and attempts to seek comfort/support from others (e.g., Bartholomew \& Horowitz, 1991; Brennan, Clark, \& Shaver, 1998), we expect that support-providers' avoidant attachment will be associated with motives (for providing secure base support) reflecting a desire to avoid negative consequences for not helping and views of their spouse as needy. Albeit for a different reason (i.e., their discomfort with intimacy), avoidant support-providers also are unlikely to report supporting their partners because they love their spouse or enjoy it. When asked about their motives for not providing a secure base for their partners, avoidant individuals are likely to report motives reflecting a belief that their spouse does not need their support, views that the spouse is difficult and unreceptive, a lack of knowledge about how to support the spouse, views that the spouse is too dependent, and views that it is stressful to support the spouse.

We expect that support-recipient attachment also should be linked with support-providers' motives for providing secure base support, to the extent that recipients play a role in influencing the quality of care that they receive (Collins \& Feeney, 2000). For example, support-providers may be especially motivated to connect with an avoidant partner when supporting their exploration behavior, and support-providers may be particularly likely to perceive an anxious partner as needy and as requiring more assistance with exploration activities. Given that anxious recipients are likely to be particularly difficult to support in this context, their partners are unlikely to report enjoyment motives for providing support and may do so primarily to avoid negative consequences from the recipient. With regard to motives for not providing secure base support, partners of anxious recipients are likely to report that their partner is too dependent on them and difficult to support, whereas partners of avoidant recipients (who value independence) are likely to report that their spouse does not need their assistance and is not accepting of it.

\section{Motivations for Providing a Secure Base Predicting Secure Base Behavior}

Motivations are important to consider because they should influence the provision of secure base support. Motivations that are more other-focused - such as supporting a partner because the provider loves his or her spouse, wants the spouse to feel good, and enjoys helping the spouse - should be linked with the effective provision of secure base support. However, motivations that are more self-focused - such as supporting a partner in order to avoid negative consequences, receive a reward, or avoid one's own goals - should be linked with the provision of less effective secure base support. Motivations for not providing secure base support (e.g., perceiving one's spouse to be unreceptive, difficult, too dependent; not approving of a partner's goals; having no knowledge, concern, or time; perceiving no spouse need; feeling that it is stressful to support one's partner, concern that the spouse's goal will 
take the spouse away) are also expected to predict the provision of less (and less effective) secure base support.

\section{Method}

The current investigation focuses the spotlight on motivations for providing (and for not providing) secure base support. Both observational and survey methods are used to examine the extent to which specific motivations are linked with attachment orientation and secure base support behavior in a sample of married couples.

\section{Participants}

Participants were 189 married couples who were recruited through newspaper advertisements and flyers, and were compensated for their participation in each of two sessions. Couples had been married for an average of 10.1 years (median $=6.0$ years), all were living together, and all were heterosexual. Each member of the couple was randomly assigned to the role of either "support-provider" or "recipient." The mean age of supportproviders was 39.2 (range $=21-82$ ), and the mean age of recipients was 39.98 (range $=18$ - 81). Ninety-nine females and 90 males were assigned to the support-provider role, and 90 females and 99 males were assigned to the recipient role. Demographics for supportproviders include: 71.9\% Caucasian, 16.7\% African American, 2\% Asian, 1.5\% Hispanic, $1 \%$ Native American, $1 \%$ other, 38.5\% high school education or some college credit, $43.8 \%$ college education, $12.4 \%$ advanced professional degree, and 5.3\% did not complete high school. Demographics for recipients include: 69.5\% Caucasian, 15.8\% African American, 2.5\% Asian, $2 \%$ Hispanic, $1.5 \%$ Native American, $1 \%$ other, $41.1 \%$ high school education or some college credit, $43.4 \%$ college education, $11.9 \%$ advanced professional degree, and $3.6 \%$ did not complete high school. In this investigation, the couple (not the individual) is the unit of analysis.

\section{Procedure}

Couples visited the laboratory for two sessions, one couple at a time, as part of a larger investigation of marital relationships. ${ }^{1}$ The two sessions were scheduled approximately one week apart.

Questionnaire Session-During the first session, couple members completed a packet of questionnaires in separate, private rooms, which included measures of attachment orientation, secure base support provision, and a future goals questionnaire.

Attachment Orientation: Each couple member (support-provider and recipient) completed an abbreviated 26-item version of Brennan, Clark, and Shaver's (1998) Experiences in Close Relationships scale, which is a well-validated measure for assessing adult attachment and contains two subscales. The avoidance subscale measures the extent to which one is comfortable with closeness and intimacy as well as the degree to which one feels that people can be relied on to be available when needed ( $\alpha=.89$ for support-providers; $\alpha=.87$ for

${ }^{1}$ This investigation was part of a larger investigation of marriage relationships; thus, participants from this sample participated in additional study procedures described elsewhere. The current set of analyses do not overlap with any other published work. 
recipients). The anxiety subscale measures the extent to which one is worried about being rejected, abandoned, or unloved ( $\alpha=.91$ for support-providers; $\alpha=.89$ for recipients). Couple members responded to each item on a scale from 1 (strongly disagree) to 7 (strongly agree) in terms of their general orientation toward close relationships. Items were slightly re-worded so that respondents answered in terms of their general orientation toward close relationships instead of their more specific orientation to romantic relationships. The avoidance and anxiety scales were positively correlated for support-providers $(r=.40, p<$. $001)$ and recipients $(r=.42, p<.001)$.

Motivations: Support-providers completed two measures of their typical motivations for providing and for not providing a secure base to their spouses, which were developed for use in this investigation. ${ }^{2}$ First, they completed a Motivations for Providing a Secure Base scale, for which they were presented with the phrase, "On occasions when I encourage or support my spouse's goals, I generally do so because...," and they responded to 32 motivation items on a scale from 1 (strongly disagree) to 6 (strongly agree). A principal components analysis indicated that the motivation items loaded on 11 factors representing the following motives (1) Avoid Negative Consequences (4 items; e.g., "I want to avoid negative consequences from my spouse (e.g., my spouse would get angry or withdraw from me)", "My partner would be angry with me if I didn't encourage or support him/her"), (2) Keep Spouse (3 items; e.g., "My spouse might not love or accept me if I didn't support his/her goals", "My spouse will be more likely to remain in the relationship if I encourage and support him/ her"), (3) Avoid Own Goals (4 items; e.g., "It's easier for me to support my spouse's goals than for me to pursue my own goals", "When I support my spouse, I don't have to think about my own goals"), (4) Gain Rewards (4 items; e.g., "I expect something in return for my encouragement and support later", "it makes me feel in control when I help and encourage my spouse"), (5) Needy Spouse (4 items; e.g., "My spouse really needs my encouragement...he/she would be reluctant to do anything otherwise", "I want my spouse to learn to be more confident"), (6) Feel Obligated (2 items; I feel obligated to encourage and support my spouse's goals; it's expected of me", "It's part of my job as a spouse"), (7) Enjoy Helping (2 items; "I truly enjoy helping my spouse", "I get a great deal of happiness and pleasure from making my partner happy"), (8) Love Spouse (2 items; "I love my spouse", "I want my spouse to be happy"), (9), Connect with Spouse (3 items; e.g., "It helps me to stay connected to my spouse", "It's a way that I can be a part of my spouse's life"), (10) Makes Spouse Feel Good (2 items; "I want my spouse to feel good about him/herself", "I want my spouse to feel good about his/her abilities"), and (11) Makes Me Feel Good (2 items; "It makes me feel good about myself when I help my spouse", "It makes me feel good about myself to know that I've helped my partner"). Table 1 presents descriptive statistics (means, standard deviations, reliability coefficients) and inter-correlations among these composite scales.

Participants also completed a Motivations for Not Providing a Secure Base scale, for which they were presented with the phrase, "On occasions when I don't encourage or support my spouse's goals, I generally don't do it because...", and they responded to 42 motivation items

\footnotetext{
${ }^{2}$ A complete copy of the secure base motivation measures can be obtained from the first author (bfeeney@andrew.cmu.edu).
} 
on a scale from 1 (strongly disagree) to 6 (strongly agree). A principal components analysis indicated that the motivation items loaded on 11 factors representing the following motives: (1) Unreceptive Spouse (4 items; e.g., "My spouse doesn't like my help or encouragement", "My spouse doesn't appreciate my helping efforts"), (2) Difficult Spouse (4 items; e.g., "My spouse is too bossy and demanding, so I don't like (or want) to help", "We always get in a fight when I try to encourage or help him/her"), (3) Spouse Too Dependent (4 items; e.g., "My spouse expects me to do everything and doesn't do enough for him/herself", "My spouse is too dependent on me"), (4) Lack of Need (2 items; "My spouse never seems to have any goals", "My spouse didn't ask for my help or encouragement"), (5) Takes Spouse Away (8 items; e.g., "I want my spouse to stay close to me and not venture too far away", "I sometimes feel left out when my spouse pursues goals that don't involve me"), (6) Disapprove of Spouse's Goals (7 items; e.g., "I don't like or approve of my spouse's goals", "the goal is not very important or worthwhile"), (7) Concern about Spouse Changing (2 items; "I don't want my spouse to change", "I don't want my spouse to interact with other people who might influence him/her in a negative way"), (8) Too Stressful (3 items; e.g., "It's too stressful for me to try to encourage and support my spouse's goals", "I prefer to maintain some distance; I'd rather not get involved"), (9) No Support Knowledge (3 items; e.g., "I don't know how to encourage or support my spouse", "I never know what kind of help or support my spouse really wants"), (10) Lack of Responsibility/Concern (2 items; "It's not really my responsibility to help and encourage him/her", "My spouse's goals are of no concern to me"), and (11) Lack of Time (3 items; e.g., "I don't have the time", "I'm sometimes too busy with my own goals and challenges"). Table 2 presents descriptive statistics (means, standard deviations, reliability coefficients) and inter-correlations among these composite scales.

Secure Base Support: Support-providers completed the 15-item measure of Secure Base Support (Feeney \& Thrush, 2010), which assesses the three characteristics of a secure base (availability during exploration, encouragement of exploration, and non-intrusiveness) elaborated in prior work (Feeney \& Thrush, 2010). The availability subscale assesses the extent to which support-providers generally make themselves available to their partners if needed during exploratory activities ( 5 items; e.g., "My spouse is usually willing to take risks and try new things because he/she knows I'll be available to help and comfort him/her if things don't turn out well," "My spouse does not generally count on me to be available to help out if he/she runs into trouble when pursuing personal goals," reverse coded). The Interference subscale assesses the extent to which support-providers generally intrude in the explorations and goal pursuits of their partners (5 items; "I sometimes interfere with my spouse's activities when he/she is exploring a challenging activity or task," "When my spouse is working on something difficult or challenging, I sometimes try to take over and do it for him/her"). The Encouragement subscale assesses the extent to which support-providers generally encourage their partner's goal strivings, personal growth, and exploration (5 items; e.g., "When my spouse tells me about something new that he/she would like to try, I usually encourage him/her to do it," "I encourage my spouse to do independent things that will help $\mathrm{him} / \mathrm{her}$ grow as a person and develop new competencies"). Support-providers rated the extent to which they agreed with each statement on a 6-point Likert scale. Reliabilities for each subscale are as follows: $\alpha=.81$ for availability, $\alpha=.85$ for interference, and $\alpha=.78$ 
for encouragement. The three subscales were modestly correlated with each other and, for parsimony, were combined into an overall index of secure base support (with higher scores indicating higher quality support).

Future Goals Questionnaire: Recipients completed a Future Goals and Plans Questionnaire (Feeney, 2004), on which they were asked to list their personal goals for the future. Each recipient was instructed to list goals that are personally relevant to him- or herself (e.g., developing a new hobby, switching jobs) and not those that involve the active participation of both couple members (e.g., having a baby). Support-receivers were instructed to list as many or as few goals as they actually had, and then they were asked to rate (a) the importance of each goal on a scale ranging from 1 (not that important to me at all) to 5 (extremely important to me) and (b) their perceived likelihood of achieving each goal on a scale ranging from 1 (not at all likely to achieve that goal) to 5 (almost certain that I'll achieve that goal). Couples discussed goals pertaining to career (30.9\%), education (10.05\%), travel (1.25\%), physical fitness (11.6\%), relationships (9.4\%), creativity (5.65\%), possessions (2.8\%), spirituality (4.7\%), personal development (7.25\%), finances $(7.25 \%)$, and other $(11.4 \%)$.

Observational Session-Approximately one week later, couples returned to the lab for an observational session, which took place in a laboratory living room. In order to help couples feel comfortable interacting in the lab, they first interacted for 5 minutes while playing a cooperative game (a version of the game Pictionary). Then, the recipient was given an index card on which his or her personal goals were listed, and the couple members were asked to discuss these goals. Their interactions were unobtrusively videotaped for 10 min and later coded for the support-providers' provision of secure base support. Upon completion of the goal discussion, the couple members completed additional aspects of the larger investigation of marital relationships, and then they were fully debriefed and thanked for their participation.

Coding of Support-Provider's Secure Base Behavior: Support-provider behaviors relevant to each of the three qualities of a secure base (availability, non-interference, and encouragement, Feeney, 2004) were coded by independent observers who were trained to reliability. The extent to which each behavior occurred was coded on well-defined 5-point rating scales. To assess interobserver reliability, intraclass correlation coefficients (ICCs) were computed (McGraw \& Wong, 1996) for all coded dimensions. Averages of the observers' ratings were used in data analysis.

Support behaviors indicating availability were coded as follows: (a) Communication of Future Availability $(\mathrm{ICC}=.71)$ : the support-provider conveys that he or she will be available to help as needed in the future attainment of the partner's goals; (b) Listening/ Attentive (ICC = .54): the support-provider displays clear signs of being focused on his or her partner and processing the partner's disclosure of information (e.g., eye contact, nods); (c) Emotional Support (ICC = .74): the support-provider is responsive to the emotional needs of the partner (e.g., by validating feelings, making empathic remarks, encouraging disclosure of feelings); and (d) Instrumental Support (ICC $=.55$ ): the support-provider 
provides actual, tangible assistance that is focused on fixing a specific goal-related problem or helping to make a plan for how a particular goal may be achieved;

Support behaviors indicating encouragement include (e) Encouragement of Goals and Autonomy (ICC $=.65$ ): the support-provider encourages the partner to pursue his or her personal goals; and (f) Confidence in Partner's Abilities (ICC $=.74$ ): the support-provider communicates confidence in the partner's ability to successfully accomplish his/her goals. Support behaviors indicating non-intrusiveness include (g) Intrusiveness/Interference (reverse-coded, ICC $=.67$ ): the support-provider either overtly or subtly interferes with the partner's goals (e.g., by inserting him- or herself into the goals, trying to change the goals, preventing the partner from pursuing the goals); and (h) Comfort With the Partner's Autonomous Goal Pursuit (ICC $=.70$ ): the support-provider behaves in a manner indicating that he or she feels comfortable with the partner's pursuit of autonomous goals.

Three summary codes representing the extent to which the support-provider provided a secure base for the partner include: (i) Support of Goals and Autonomous Exploration (ICC $=.72$ ): the support-provider supports his or her partner's autonomous pursuit of goals (e.g., by facilitating dialogue about the goals, expressing understanding and respect for the partner and the partner's goals); (j) Overall Support Effort (ICC $=.80$ ): the support-provider demonstrates an active effort to be sensitive and responsive to the partner and his or her goals and goal-related problems throughout the discussion; and (k) Open Communication (ICC $=.76$ ): the couple engages in an open and fluid conversation about the supportrecipient's goals in which both partners freely express emotion and comfortably share their thoughts and feelings; the conversation is warm, accepting, comfortable, and balanced.

For use in data analyses, a composite index representing the support-providers' observed responsive secure base support was computed by averaging ratings for all coded behaviors (mean $r=.53, p<.001 ; \alpha=.93$ ).

\section{Results}

Correlational and regression analyses were conducted to examine the predicted associations (a) between attachment orientation and motivations and (b) motivations and secure base behavior. We also examined links between attachment orientation and secure base behavior to complement the results of one prior investigation that has documented this link (Feeney \& Thrush, 2010).

\section{Attachment Orientation as a Predictor of Motivations}

Motivations for Providing a Secure Base-We began by computing correlations between support-providers' attachment dimensions and their motivations for providing a secure base to their spouse. As shown in Table 3, attachment orientation is strongly linked with specific motives for providing secure base support. Support-providers who are higher in either type of insecurity (avoidance or anxiety) report that, when they provide secure base support to their partners, they do so in order to avoid negative consequences for not doing so, to keep their spouse in the relationship, to avoid pursuing their own goals, and because they perceive the spouse to be needy or overly-dependent on them. Support-providers who 
are higher in either type of insecurity also report that they do not provide a secure base because they enjoy it or because they love their spouse. Each attachment orientation was also uniquely associated with specific motives: Support-provider anxiety was positively associated with motives for providing a secure base including feelings of obligation, wanting to receive a reward for providing the support, and a desire to connect with the spouse. Support-provider avoidance was negatively associated with helping in order to make the spouse feel good.

In supplementary analyses, we conducted hierarchical regression analyses to examine the independent contributions of each attachment dimension and to explore the anxiety $x$ avoidance interactions. We predicted each of the motives from the support-providers' anxiety and avoidance on Step 1, and the interaction on Step 2. The results from Step 1 (see Table 4) are consistent with the correlational analyses, with a few exceptions. Most notably, the anxiety (but not avoidance) dimension was a significant unique predictor of motives related to keeping one's spouse and avoiding one's own goals. The regression analyses also revealed three significant anxiety $\times$ avoidance interactions predicting reward $(p=.01)$, needy spouse ( $p=.05)$, and obligation ( $p=.03$ ) motives. To probe these interactions, we plotted the predicted values of each dependent variable at $1 \mathrm{SD}$ above and below the mean on anxiety and avoidance (Aiken \& West, 1991). These analyses revealed a similar pattern across the three motives; secure support-providers (low anxiety and low avoidance) were least likely to report these specific motives whereas preoccupied (high anxiety and low avoidance) and fearful (high anxiety and high avoidance) were most likely to do so. ${ }^{3}$

Next we considered the extent to which support-recipient attachment orientation was correlated with motivations for providing a secure base (see Table 3). Results indicated that when recipients were high in attachment anxiety, their spouses reported that when they provide secure base support, they typically do so to avoid negative consequences and because their partner is needy/too dependent on them - and not because they love their partner and enjoy helping him/her. There were non-significant trends for spouses of anxious partners to report helping in order to keep the spouse, but not to connect with him/her or because it makes the recipient feel good. Recipients' attachment avoidance was not as strongly linked with their spouses' motives for providing secure base support. Spouses of avoidant recipients reported that they do not provide secure base support in order to connect with the spouse.

In hierarchical regression analyses we examined the independent contributions of each attachment dimension and explored the anxiety $\times$ avoidance interactions for supportrecipients. The results from Step 1 (see Table 4) are highly consistent with the correlational results. Spouses of anxious recipients are more likely to provide support to avoid negative consequences and because they perceive their spouses to be needy and dependent; they are less likely to provide support because they love their spouses or enjoy helping them. In addition, there was a non-significant trend indicating that spouses of avoidant recipients are

${ }^{3}$ For reward motives, the predicted values were 2.0 for secure support-providers (low anxiety, low avoidance), 3.2 for preoccupied (high anxiety, low avoidance), 2.4 for dismissing (low anxiety, high avoidance) and 2.8 for fearful (high anxiety, high avoidance). For obligation motives, the predicted values were 3.6 for secure, 4.6 for preoccupied, 3.9 for dismissing, and 4.1 for fearful. For needy partner motives, the predicted values were 3.0 for secure, 3.8 for preoccupied, 3.6 for dismissing, and 3.8 for fearful. 
less likely to provide support because they perceive that their spouses are needy. There were no significant anxiety $\times$ avoidance interactions for support-recipients.

Motivations for Not Providing a Secure Base-Next, we examined correlations between attachment orientation and support-providers' motives for not providing a secure base to their spouses. As shown in Table 5, support-providers who were high in either type of insecurity (avoidance or anxiety) reported that when they do not support their spouses, it is because they perceive the spouse to be unreceptive and difficult, the spouse's goals will take the spouse away from them, the spouse is too dependent, they do not approve of the spouse's goals, they have no knowledge about how to support the spouse, they are not concerned about the spouse, and it is too stressful to support the spouse in this way. Supportprovider anxiety was uniquely associated with motives for not supporting one's spouse including views that the spouse does not need support, concerns that the spouse might change if he/she pursued goals, and a lack of time.

Once again, we conducted supplementary regression analyses to examine the independent contributions of each attachment dimension and to explore the anxiety $\times$ avoidance interactions. Results from Step 1 (see Table 6) are highly consistent with the correlational analyses, with a few exceptions. Most notably, the anxiety (but not avoidance) dimension was a significant unique predictor of motives reflecting concern that the spouse's goals will take him/her away, disapproval of the spouse's goals, and concern that the spouse's goals will lead him/her to change. There were no significant anxiety $\times$ avoidance interactions.

Support-recipient attachment orientation was also correlated with some of the supportproviders' motives for not providing secure base support (see Table 5). Specifically, recipient anxiety was positively associated with support-providers' reports of motives reflecting that they have an unreceptive and difficult spouse, and that their spouse is too dependent on them. Recipient avoidance was associated with support-providers' reports of motives reflecting that the spouse is unreceptive and does not need their support.

Finally, we conducted hierarchical regression analyses predicting each of the motives from the support-recipient's attachment dimensions. Results from Step 1 (see Table 6) were highly consistent with the correlational findings summarized above. Results from Step 2 revealed one significant anxiety $\times$ avoidance interaction predicting no knowledge motives $(p$ $<.05)$. A plot of this interaction indicated that spouses of insecure (versus secure) recipients were more likely to report that when they do not support their spouses, it is because they are uncertain about how to support and encourage them. ${ }^{4}$

\section{Motivations Predicting Secure Base Behavior}

Motivations for Providing a Secure Base-We next examined associations between motivations for providing secure base support and secure base support provision.

Assessments of secure base support provision included support-provider reports of the

\footnotetext{
${ }^{4}$ For no knowledge motives, the predicted values were 2.2 for secure support-recipients (low anxiety, low avoidance), 2.9 for preoccupied (high anxiety, low avoidance), 2.9 for dismissing (low anxiety, high avoidance) and 2.6 for fearful (high anxiety, high avoidance).
} 
support that they typically provide, as well as secure base support observed in a laboratory discussion by independent raters.

As shown in Table 7, results indicated that support-provider motives were strongly predictive of their secure base behavior. Support-providers who reported that they support their partners because they love them and enjoy supporting them provided more responsive secure base support (both as reported by the support-providers and as observed in the laboratory by independent raters). Support-providers who reported motives including desires to avoid negative consequences, to keep their spouse in the relationship, or to have a reward for helping, provided less secure base support (both as reported by observers and supportproviders). Observers' ratings of responsive support provision were additionally associated with motives reflecting a desire to connect with one's spouse, and observers' ratings of less responsive support provision were linked with support-provider motives reflecting views that the spouse is needy. Support-providers' reports of responsive support provision were additionally associated with motives reflecting desires to make both the spouse and oneself feel good. Finally, support-providers' reports of less responsive support provision were associated with motives reflecting a desire to avoid one's own goals by helping the spouse.

Motivations for Not Providing a Secure Base-Results indicated that every assessed support-provider motivation for not providing a secure base was significantly and negatively associated with support-provider reports of their typical secure base support provision (see Table 8). Specifically, less responsive secure base support provision was linked with motives for not helping that include having an unreceptive, difficult, and overly-dependent spouse; concerns that the spouse's goals will take him/her away and concern that the spouse might change; disapproval of the spouse's goals; a lack of concern, time, and knowledge about how to support one's spouse; viewing the spouse as not needing support; and perceptions that it is too stressful to support the spouse. Interestingly, unreceptive, difficult, and overly-dependent partner motives for not helping, as well as motives reflecting views that the spouse does not need support and that it is too stressful to support the spouse, were associated with less secure base support provision as coded by independent observers during the laboratory discussion of the recipients' goals.

\section{Attachment Orientation Predicting Secure Base Support}

Consistent with prior work (Feeney \& Thrush, 2010), attachment orientation was significantly associated with the provision of secure base support (as reported by the support-providers and as observed in the laboratory by independent raters). As shown in Table 9, support-providers who were higher in attachment anxiety or avoidance were rated as less effective support providers during their partner's goal discussions; they also reported providing less effective secure base support during their typical secure base interactions with their partners. With regard to recipient attachment, only recipient anxiety was significantly associated with observed secure base support during the laboratory discussion; anxious support-recipients received less responsive support from their partners. Supplementary regression analyses revealed no significant anxiety $\times$ avoidance interactions for supportproviders or support-recipients. 


\section{Discussion}

This investigation examined the importance of underlying motivations in predicting secure base support behavior, as well as the extent to which support motivations are predicted by individual differences in attachment orientation. We contributed to the existing literature by first identifying and developing measures to assess specific motivations for providing, and for not providing, secure base support, and then by establishing links between these motives and both attachment orientation and secure base behavior.

First, we found that spouses have a variety of motives for providing, and for not providing, secure base support within their relationships. Motivations for providing support include both relatively altruistic motives (e.g., loving the spouse, wanting the spouse to be happy, enjoying helping one's spouse), as well as clearly egoistic motives (e.g., avoiding negative consequences, feeling obligated, wanting a reward, avoiding one's own goals). Motivations for not providing support included concerns about having an unreceptive, difficult, or overly-dependent spouse; disapproval of the spouse's goals; concerns that the goals will take the spouse away or cause the spouse to change; and a perceived lack of time, concern, or need.

Second, results indicated that support-provider attachment orientation was strongly associated with these motives in theoretically-expected ways. Support-provider insecurity (both avoidance and anxiety) was linked with more egoistic motives for providing a secure base, but the specific pattern of motives differed for the two forms of insecurity. Anxious support-providers were egoistically motivated to avoid negative consequences, to gain rewards for helping, and because they perceived their spouse to be needy and felt obligated to help them. Anxious support-providers were also motivated by the desire to keep their spouse, to connect with their spouse, and to avoid the pursuit of their own goals. Avoidant support-providers were egoistically motivated to avoid negative consequences and because they perceived their spouses as needy. As predicted, insecure support-providers were also less altruistically motivated to provide secure base support. Anxious and avoidant supportproviders were less likely to provide help because they love their spouses or enjoy helping them; and avoidant support-providers were less motivated by the desire to make their spouse feel good. These results are consistent with theory and research indicating that anxious attachment leads one to be self-focused and to direct attention toward attachment figures in a hypervigilant way (e.g., helping to keep the spouse, to stay connected to the spouse), whereas avoidant attachment leads one to emphasize independence and restrict intimacy (Bartholomew \& Horowitz, 1991; Brennan et al., 1998).

When asked why they do not provide a secure base, individuals high in either form of insecurity (avoidance or anxiety) reported more negative motives for not helping, but the specific pattern of motives differed for the two forms of insecurity. For anxious supportproviders, their motives reflected pessimistic views of their partner, feelings of threat concerning their spouse's independent goal pursuits, and a lack of skills and resources. Specifically, they reported motives indicating that their spouses were unreceptive, difficult, and not in need of their support; they also reported concerns that supporting their spouses' goals will take their spouse away from them or cause their spouse to change; and that they 
do not approve of their spouse's goals. Anxious support-providers also reported that they lacked the knowledge, time, and responsibility for supporting their spouse's goal pursuits; and that it was too stressful to support their spouse. The pattern for avoidant supportproviders reflected negative views of the partner, discomfort providing support, and lack of skills. Specifically, avoidant support-providers reported not helping because their partner is perceived to be unreceptive, difficult, and too needy/dependent. They also reported not helping because it was too stressful, because they lacked knowledge about how to help their partner, and because they lacked a sense of responsibility/concern for their partner's goal pursuits. Taken together, these motives for not providing a secure base reflect anxious individuals' concerns about rejection and abandonment and avoidant individuals' concerns about emotional intimacy (e.g., Hazan \& Shaver, 1987; Collins \& Read, 1990; Simpson, 1990; see Cassidy \& Shaver, 2008, and Mikulincer \& Shaver, 2007, for reviews). These results are also consistent with evidence indicating that couples are non-randomly paired in their attachment orientation and that anxious and avoidant pairings are surprisingly stable over time (Kirkpatrick \& Davis, 1994) - evidence suggesting that motives reflecting a difficult or unresponsive spouse are based in some degree of reality.

Consistent with this idea, recipient attachment orientation was also linked with supportprovider motives, albeit to a substantially lesser extent than support-provider attachment. Corroborating theory and research indicating that avoidant individuals emphasize independence and restrict intimacy (Mikulincer \& Shaver, 2007), and thus may not be receptive to particular forms of support (Simpson, Winterheld, Rholes, \& Orina, 2007), recipient avoidance was linked with support-provider motives reflecting a lack of desire to connect with the spouse, and views that the spouse is unreceptive and does not need their support. Interestingly, recipient anxiety was linked with support-provider motives including helping to avoid negative consequences and because the spouse is needy - but not because they love the spouse and enjoy helping - and with support-provider motives for not helping including views that the spouse is unreceptive, difficult, and too dependent - all likely to reflect the difficulty of supporting an anxious individual who is hypersensitive to the possibility of rejection/abandonment, and who would prefer to merge completely with the partner (e.g., Cassidy \& Shaver, 2008; Mikulincer \& Shaver, 2007).

Perhaps of utmost importance was to establish links between support-provider motives and actual secure base support behavior that is enacted in relevant contexts. Consistent with predictions, support-providers' motives were strongly linked to their enacted support - not only as reported by the support-providers themselves, but also as observed by independent raters during couples' discussions of future goals. Specifically, more altruistic (and less egoistic) motives for providing support (e.g., love spouse, enjoy helping, desire to connect with the spouse, makes the spouse feel good, makes me feel good) were linked with responsive secure base support provision, whereas more egoistic motives for providing support (e.g., to avoid negative consequences, keep the spouse, avoid own goals, want a reward) were linked with unresponsive secure base support provision. In addition, motives for not providing secure base support, which predominantly reflect egoistic motives (e.g., unreceptive spouse, difficult spouse, goals will take spouse away, spouse is too dependent, it's too stressful, no time or concern, no knowledge of how to support spouse, don't approve of spouse's goals) were linked with the provision of unresponsive secure base support. 
Taken together, these results indicate that underlying motives do, in fact, predict the quality of support that is provided, and that the most responsive support-providers are those who are more altruistically motivated by empathic concern (Batson \& Shaw, 1991) and more intrinsically motivated (Deci \& Ryan, 2000; Ryan \& Deci, 2000) to care for their partners. These results also provide strong evidence that underlying motivations are important mechanisms that shape the quality of secure base support.

In sum, this investigation contributes to existing research by focusing the spotlight on motivations for providing (and for not providing) secure base support, by providing measures of these motivations, by identifying what these motives are, and by showing how they are linked to both attachment orientation and secure base support provision -- none of which has been examined previously. Additional strengths of this investigation are that both observational and survey methods were used to consider these processes in a large sample of established married couples. Although we cannot make causal claims based on this initial work, and experimental studies that manipulate motives will be important next steps in this line of work, this investigation provides an important foundation for future work that establishes motivations as important mechanisms that underlie the effective or ineffective provision of relational support.

\section{Acknowledgments}

This research was supported by grants from the National Institute of Mental Health (MH066119) and the National Science Foundation (BCS0424579) to the first author. Preparation of this paper was supported by a grant from the Fetzer Foundation to the second author.

\section{References}

Aiken, LS.; West, SG. Multiple Regression: Testing and interpreting interactions. Sage; Newbury Park, CA: 1991.

Bartholomew K, Horowitz LM. Attachment styles among young adults: A test of a four-category model. Journal of Personality and Social Psychology. 1991; 61:226-244. [PubMed: 1920064]

Batson CD, Shaw LL. Evidence for altruism: Toward a pluralism of prosocial motives. Psychological Inquiry. 1991; 2:107-122.

Bowlby, J. A secure base. Basic Books; New York: 1988.

Brennan, KA.; Clark, CL.; Shaver, PR. Self-report measurement of adult attachment: An integrative overview.. In: Simpson, J.; Rholes, WS., editors. Attachment theory and close relationships. Guilford Press; 1998.

Canevello A, Crocker J. Creating good relationships: Responsiveness, relationship quality, and interpersonal goals. Journal of Personality and Social Psychology. 2010; 99:78-106. [PubMed: 20565187]

Cassidy, J.; Shaver, P. Handbook of attachment: Theory, research, and clinical applications. Guilford Press; New York, NY: 1999.

Clark MS, Mills J. The difference between communal and exchange relationships: What it is and is not. Personality and Social Psychology Bulletin. 1993; 19:684-691.

Collins N,L, Feeney BC. A safe haven: Support-seeking and caregiving processes in intimate relationships. Journal of Personality and Social Psychology. 2000; 78:1053-1073. [PubMed: 10870908]

Collins NL, Read SJ. Adult attachment, working models, and relationship quality in dating couples. Journal of Personality and Social Psychology. 1990; 58:644-663. [PubMed: 14570079] 
Crocker J, Canevello A. Creating and undermining social support in communal relationships: The role of compassionate and self-image goals. Journal of Personality \& Social Psychology. 2008; 95:555-575. [PubMed: 18729694]

Crowell J, Treboux D, Gao Y, Fyffe C, Pan H, Waters E. Assessing secure base behavior in adulthood: Development of a measure, links to adult attachment representations and relations to couples' communication and reports of relationships. Developmental Psychology. 2002; 38:679-693. [PubMed: 12220047]

Deci EL, Ryan RM. The "what" and "why" of goal pursuits: Human needs and the self-determination of behavior. Psychological Inquiry. 2000; 11:227-268.

Feeney BC. A secure base: Responsive support of goal strivings and exploration in adult intimate relationships. Journal of Personality and Social Psychology. 2004; 87:631-648. [PubMed: 15535776]

Feeney BC. The dependency paradox in close relationships: Accepting dependence promotes independence. Journal of Personality and Social Psychology. 2007; 92:268-285. [PubMed: 17279849]

Feeney BC, Collins NL. Predictors of caregiving in adult intimate relationships: An attachment theoretical perspective. Journal of Personality and Social Psychology. 2001; 80:972-994. [PubMed: 11414378]

Feeney BC, Collins NL. Motivations for caregiving in adult intimate relationships: Influences on caregiving behavior and relationship functioning. Personality and Social Psychology Bulletin. 2003; 29:950-968. [PubMed: 15189615]

Feeney BC, Collins NL. A new look at social support: A theory of thriving through relationships. 2012 Manuscript submitted for review.

Feeney BC, Thrush RL. Relationship Influences on Exploration in Adulthood: The Characteristics and Function of a Secure Base. Journal of Personality and Social Psychology. 2010; 98:57-76. [PubMed: 20053031]

Hazan C, Shaver PR. Romantic love conceptualized as an attachment process. Journal of Personality and Social Psychology. 1987; 52:511-524. [PubMed: 3572722]

Kirkpatrick LA, Davis KE. Attachment style, gender, and relationship stability: A longitudinal analysis. Journal of Personality and Social Psychology. 1994; 66:502-512. [PubMed: 8169762]

Kunce, LJ.; Shaver, PR. An attachment-theoretical approach to caregiving in romantic relationships.. In: Bartholomew, K.; Perlman, D., editors. Advances in personal relationships. Vol. 5. Jessica Kingsley; London: 1994. p. 205-237.

Marvin R, Cooper G, Hoffman K, Powell B. The circle of security project: Attachment-based intervention with caregiver-preschool child dyads. Attachment \& Human Development. 2002; 4:107-124. [PubMed: 12065033]

McGraw KO, Wong SP. Forming inferences about some intraclass correlation coefficients. Psychological Methods. 1996; 1:30-46.

Mikulincer M, Shaver PR. Boosting attachment security to promote mental health, prosocial values, and inter-group tolerance. Psychological Inquiry. 2007; 18:139-156.

Monin JK, Schulz R, Feeney BC, Cook TB. Attachment insecurity and perceived partner suffering as predictors of personal distress. Journal of Experimental Social Psychology. 2010; 46:1143-1147. [PubMed: 21057662]

Reis, HT.; Clark, MS.; Holmes, JG. Perceived partner responsiveness as an organizing construct in the study of intimacy and closeness.. In: Mashek, DJ.; Aron, A., editors. Handbook of closeness and intimacy. Erlbaum; Mahwah, NJ: 2004. p. 415-428.

Ryan RM, Deci EL. Self-determination theory and the facilitation of intrinsic motivation, social development, and well-being. American Psychologist. 2000; 55:68-78. [PubMed: 11392867]

Simpson JA. Influence of attachment styles on romantic relationships. Journal of Personality and Social Psychology. 1990; 59:971-980.

Simpson JA, Rholes WS, Nelligan JS. Support seeking and support giving within couples in an anxiety-provoking situation: The role of attachment styles. Journal of Personality and Social Psychology. 1992; 62:434-446. 
Simpson JA, Winterheld HA, Rholes WS, Orina MM. Working models of attachment and reactions to different forms of caregiving from romantic partners. Journal of Personality and Social Psychology. 2007; 93:466-477. [PubMed: 17723060]

Waters E, Cummings E. A secure base from which to explore close relationships. Child Development. 2000; 71:164-172. [PubMed: 10836570]

Williamson GM, Clark MS, Pegalis LJ, Behan A. Affective consequences of refusing to help in communal and exchange relationships. Personality and Social Psychology Bulletin. 1996; 22:3447. 


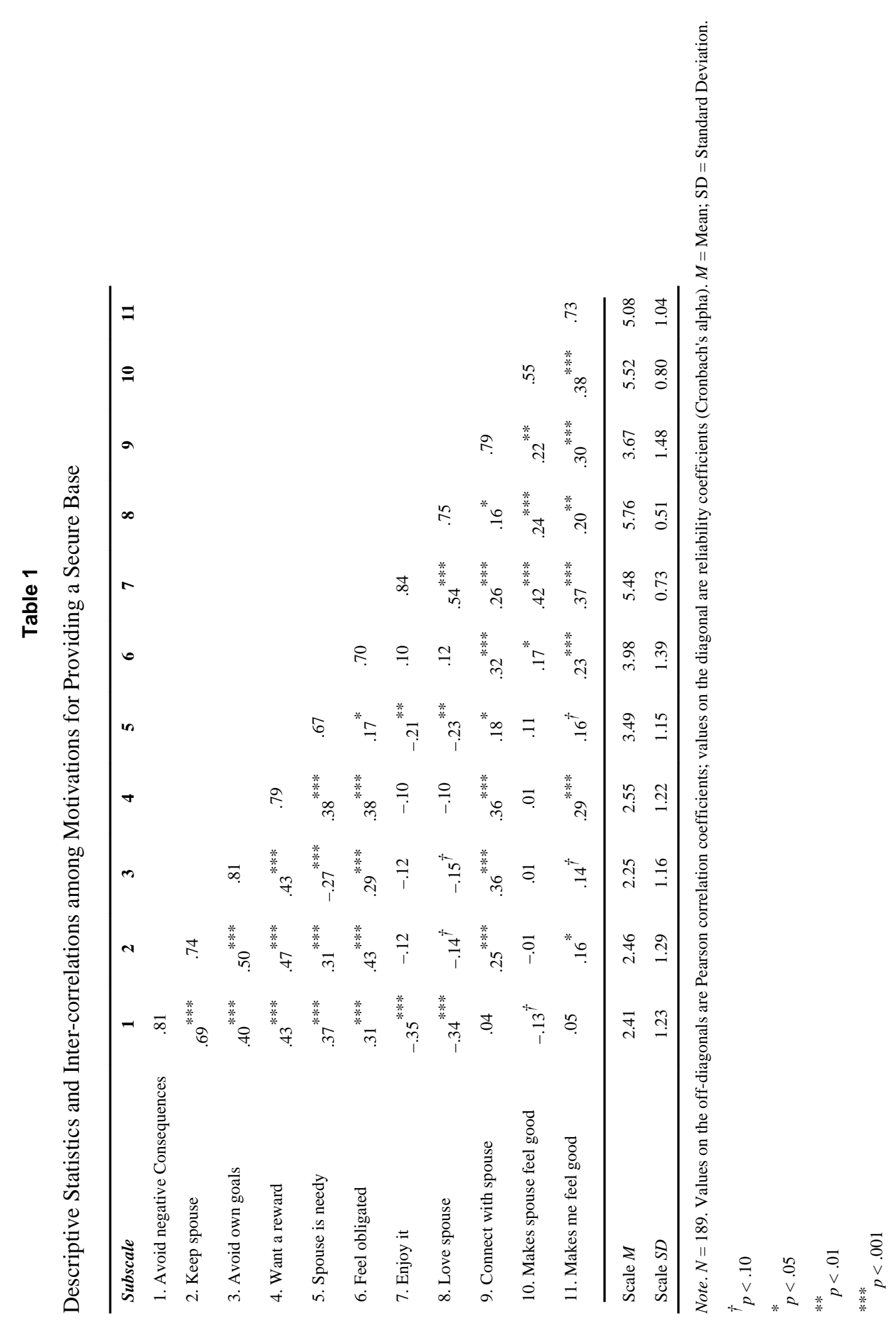




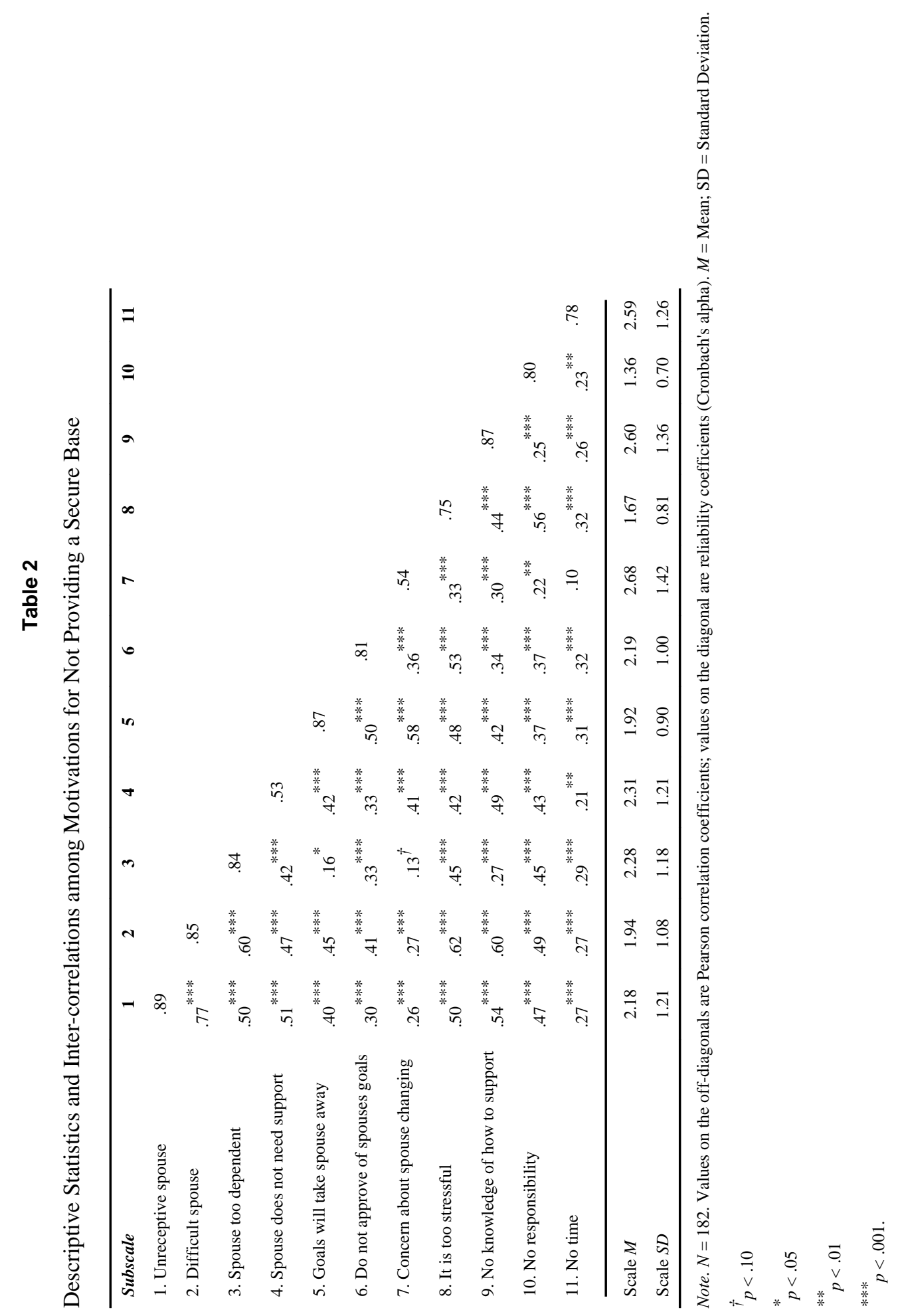


Table 3

Correlations between attachment dimensions and motives for providing secure base support

\begin{tabular}{lcccc}
\hline & Support-Provider Anxiety & Support-Provider Avoidance & Recipient Anxiety & Recipient Avoidance \\
\hline Avoid negative consequences & $.38^{* * *}$ & $.32^{* * *}$ & $.22^{* *}$ & .07 \\
Keep spouse & $.34^{* * *}$ & $.25^{* * *}$ & $.14^{\dagger}$ & .09 \\
Avoid own goals & $.2^{* * *}$ & $.23^{* *}$ & .10 & .00 \\
Want a reward & $.31^{* * *}$ & $.13^{\dagger}$ & -.08 & .03 \\
Spouse is needy & $.23^{* * *}$ & $.20^{* *}$ & $.22^{* *}$ & -.02 \\
Feel obligated & $.18^{* *}$ & .03 & -.09 & $-.14^{\dagger}$ \\
Enjoy it & $-.16^{*}$ & $-.17^{*}$ & $-.17^{*}$ & -.07 \\
Love spouse & $-.22^{* *}$ & $-.22^{* *}$ & $-.22^{* *}$ & -.06 \\
Connect with spouse & $.24^{* * *}$ & .02 & $-.13^{\dagger}$ & $-.17^{*}$ \\
Makes spouse feel good & -.05 & $-.16^{*}$ & -.06 & .02 \\
Makes me Feel good & .09 & -.05 & $-.14^{\dagger}$ & .03 \\
\hline
\end{tabular}

Note. $N=185$ to 189 .

${ }^{\dagger} p<.10$

* $p<.05$

$* *$ p $<.01$

*** $p<.001$ 
Table 4

Regression analyses predicting motives for providing secure base support

\begin{tabular}{lcccc}
\hline & \multicolumn{2}{c}{ Support Provider's Attachment Dimensions } & \multicolumn{2}{c}{ Support-Recipient's Attachment Dimensions } \\
\cline { 2 - 3 } & Anxiety & Avoidance & Anxiety & Avoidance \\
\hline Avoid negative consequences & $.31^{* * *}$ & $.20^{* *}$ & $.24^{* *}$ & -.03 \\
Keep spouse & $.28^{* * *}$ & $.13^{\dagger}$ & .11 & .04 \\
Avoid own goals & $.40^{* * *}$ & .08 & .13 & -.06 \\
Want a reward ${ }^{* *}$ & $.33^{* * *}$ & .01 & -.09 & .06 \\
Spouse is needy ${ }^{a}$ & $.20^{* *}$ & $.14^{\dagger}$ & $.29^{* * *}$ & $-.15^{\dagger}$ \\
Feel obligated ${ }^{a}$ & $.21^{* *}$ & -.05 & -.03 & -.12 \\
Enjoy it & -.11 & $-.13^{\dagger}$ & $-.16^{*}$ & .01 \\
Love spouse & $-.15^{\dagger}$ & $-.17^{*}$ & $-.23^{* *}$ & .04 \\
Connect with spouse & $.30^{* * *}$ & -.10 & -.07 & -.13 \\
Makes spouse feel good & .01 & $-.17^{*}$ & -.08 & .06 \\
Makes me feel good & $.14^{\dagger}$ & -.11 & $-.15^{\dagger}$ & .05 \\
\hline
\end{tabular}

Note. $N=184$ to 187 . Tabled values are standardized regression coefficients ( $\beta \mathrm{s})$.

${ }^{a}$ For this dependent variable, there was a significant support-provider anxiety $\times$ avoidance interaction.

${ }^{\dagger} p<.10$

* $p \leq .05$

$* * \quad p \leq .01$

*** $p \leq .001$ 
Table 5

Correlations between attachment dimensions and motives for not providing secure base support

\begin{tabular}{|c|c|c|c|c|}
\hline & Support-Provider Anxiety & Support-Provider Avoidance & Recipient Anxiety & Recipient Avoidance \\
\hline Unreceptive spouse & $.38^{* * *}$ & $.29^{* * *}$ & $.16^{*}$ & $.20^{* *}$ \\
\hline Difficult spouse & $.41^{* * *}$ & $.38^{* * *}$ & $.23^{* *}$ & .10 \\
\hline Spouse is too dependent & $.24^{* * *}$ & $.31^{* * *}$ & $.32^{* * *}$ & .04 \\
\hline Spouse does not need support & $.25^{* * *}$ & .03 & .09 & $.18^{*}$ \\
\hline Goals will take spouse away & $.45^{* * *}$ & $.17^{*}$ & .03 & .10 \\
\hline $\begin{array}{l}\text { Do not approve of spouse's } \\
\text { goals }\end{array}$ & $.30^{* * *}$ & $.21^{* *}$ & .08 & -.04 \\
\hline $\begin{array}{l}\text { Concern about spouse } \\
\text { changing }\end{array}$ & $.28^{* * *}$ & $.13^{\dagger}$ & .03 & .08 \\
\hline It is too stressful & $.24^{* * *}$ & $.33^{* * *}$ & .05 & -.04 \\
\hline $\begin{array}{l}\text { No knowledge about how to } \\
\text { support spouse }\end{array}$ & $.37^{* * *}$ & $.34^{* * *}$ & .12 & .11 \\
\hline No responsibility/concern & $.24^{* * *}$ & $.20^{* *}$ & .09 & .11 \\
\hline No time & $.24^{* * *}$ & .16 & .01 & -.11 \\
\hline
\end{tabular}

Note. $N=176$ to 182 .

${ }^{\dagger} p<.10$

$*$

$p \leq .05$

$* *$ $p \leq .01$

*** $p \leq .001$ 
Table 6

Regression analyses predicting motives for not providing secure base support

\begin{tabular}{lcccc}
\hline & \multicolumn{2}{l}{ Support Provider's Attachment Style } & \multicolumn{2}{l}{ Support-Recipient's Attachment Style } \\
\cline { 2 - 3 } & Anxiety & Avoidance & Anxiety & Avoidance \\
\hline Unreceptive spouse & $.31^{* * *}$ & $.19^{*}$ & .11 & $.17^{*}$ \\
Difficult spouse & $.32^{* * *}$ & $.25^{* * *}$ & $.23^{* *}$ & .02 \\
Spouse is too dependent & .12 & $.27^{* * *}$ & $.37^{* * *}$ & -.10 \\
Spouse does not need support & $.27^{* * *}$ & -.07 & .02 & $.17^{*}$ \\
Goals will take spouse away & $.45^{* * *}$ & .00 & -.02 & .10 \\
Do not approve of spouse's goals & $.25^{* * *}$ & .11 & .09 & -.09 \\
Concern about spouse changing & $.28^{* * *}$ & .04 & .02 & .08 \\
It is too stressful & $.14^{\dagger}$ & $.27^{* * *}$ & .09 & -.08 \\
No knowledge about how to support spouse ${ }^{* * *}$ & $.28^{* * *}$ & $.22^{* *}$ & .07 & .06 \\
No responsibility/concern & $.18^{*}$ & $.14^{\dagger}$ & .05 & .11 \\
No time & $.21^{* *}$ & .09 & .07 & -.11 \\
\hline
\end{tabular}

Note. $N=174$ to 177 . Tabled values are standardized regression coefficients ( $\beta \mathrm{s})$.

${ }^{a}$ For this dependent variable, there was a significant support-recipient anxiety $\times$ avoidance interaction.

${ }^{\dagger} p<.10$

* $p \leq .05$

$* * \quad p \leq .01$

$* * * \quad \leq .001$ 
Table 7

Correlations between motives for providing secure base support and support provision

\begin{tabular}{lcc}
\hline & Observed Responsive Secure Base Support & $\begin{array}{c}\text { Typical Secure Base Support Reported by Support- } \\
\text { Provider }\end{array}$ \\
\hline Avoid negative consequences & $-.24^{* * *}$ & $-.39^{* * *}$ \\
Keep spouse & $-.17^{*}$ & $-.30^{* * *}$ \\
Avoid own goals & -.08 & $-.31^{* * *}$ \\
Want a reward & $-.18^{*}$ & $-.34^{* * *}$ \\
Spouse is needy & $-.28^{* * *}$ & -.09 \\
Feel obligated & -.02 & -.08 \\
Enjoy it & $.23^{* *}$ & $.41^{* * *}$ \\
Love spouse & $.27^{* * *}$ & $.32^{* * *}$ \\
Connect with spouse & $.17^{*}$ & -.03 \\
Makes spouse feel good & .09 & $.35^{* * *}$ \\
Makes me feel good & .00 & $.24^{* * *}$ \\
\hline
\end{tabular}

Note. $N=162$ to 163 for observed and $N=180$ to 181 for reported.

$\dagger_{p}<.10$

* $p \leq .05$

** $p \leq .01$

$* * * x \leq .001$ 
Table 8

Correlations between motives for not providing secure base support and support provision

\begin{tabular}{lcc}
\hline & $\begin{array}{c}\text { Observed Responsive Secure Base } \\
\text { Support }\end{array}$ & $\begin{array}{c}\text { Typical Secure Base Support Reported by } \\
\text { Support-Provider }\end{array}$ \\
\hline Unreceptive spouse & $-.35^{* * *}$ & $-.35^{* * * *}$ \\
Difficult spouse & $-.33^{* * *}$ & $-.38^{* * *}$ \\
Spouse is too dependent & $-.31^{* * *}$ & $-.25^{* * *}$ \\
Spouse does not need support & $-.27^{* * *}$ & $-.20^{* *}$ \\
Goals will take spouse away & -.08 & $-.36^{* * *}$ \\
Do not approve of spouse's goals & -.11 & $-.23^{* *}$ \\
Concern about spouse changing & -.12 & $-.16^{*}$ \\
It is too stressful & $-.18^{*}$ & $-.41^{* * *}$ \\
No knowledge about how to support spouse & -.09 & $-.26^{* * *}$ \\
No responsibility/concern & -.08 & $-.30^{* * *}$ \\
No time & -.06 & $-.25^{* * *}$ \\
\hline
\end{tabular}

Note. $N=154$ to 156 for observed and $N=176$ to 178 for reported.

$\dagger p<.10$

* $p \leq .05$

**

*** $\leq .01$

$* * * x \leq .001$ 
Table 9

Correlations between attachment dimensions and support provision

\begin{tabular}{lcc}
\hline & Observed Responsive Secure Base Support & Typical Secure Base Support Reported by Support-Provider \\
\hline$\underline{\text { Support-Provider }}$ & $-.21^{* *}$ & $-.31^{* * *}$ \\
Anxiety & $-.18^{*}$ & $-.30^{* * *}$ \\
Avoidance & & -.09 \\
Support-Recipient & $-.16^{*}$ & -.03 \\
Anxiety & -.08 & \\
Avoidance & &
\end{tabular}

Note. $N=162$ to 165 for observed and $N=179$ to 182 for reported.

$\dagger p<.10$

* $p \leq .05$

$* *$ $\quad \leq .01$

$* * * \quad p \leq .001$ 